\title{
Peltojen rikkitase on negatiivinen
}

\author{
Jouko Kleemola ja Jari Peltonen
}

\section{Kemira GrowHow, Luoteisrinne 2, FI-02271 Espoo, jouko.kleemola@kemira-growhow.com}

Ravinnetutkimuksissa keskitytään usein typen ja fosforin vaikutuksiin satoon ja laatuun. Syynä tähän on todennäköisesti se, että näiden ravinteiden lisäannosten on todettu useimmiten vaikuttavan kasveihin ja ilman vuosittaista esimerkiksi lannoitteilla annettavaa ravinnetäydennystä satotasot lähtevät laskuun. Viime aikoina ravinteista vähemmälle huomiolle on jäänyt rikki. Rikki on määrällisesti fosforiin verrattava ravinne, jos asiaa tarkastellaan maksimikasvuun tarvittavina määrinä kasvissa. Osasyynä tämän päivän vähäiseen tutkimukseen ovat varmaankin 10 - 20 vuoden takaiset kokeet, joissa rikillä saatiin hyvin harvoin näkyviä vaikutuksia kasveihin. Viitteitä kasvien rikin puutteesta on alkanut ilmetä vasta aivan viime vuosina. Rikin puutteen yleistymistä on osattu odottaa, koska aiemmin merkittävä rikkilähde eli rikkilaskeuma on pienentynyt oleellisesti vuoden 1980 yli $10 \mathrm{~kg} / \mathrm{ha}$ tasosta tämän päivän muutamaan kiloon hehtaarille. Laskeuman ja lannoitteiden käytön pienenemisestä seuraa, että lannoitteiden ja laskeuman mukana pelloille tuleva rikkimäärä on yhteensä suurin piirtein samansuuruinen sadon mukana pellolta poistuvan rikkimäärän kanssa. Kun rikin huuhtouma saattaa olla savimaillakin jopa $20 \mathrm{~kg} / \mathrm{ha}$ vuosi, pelloilta poistuu nykyään rikkiä selvästi enemmän kuin mitä sinne lisätään. Laskennallisen puutetilariskin lisäksi modernit kehittyneet kasvianalyysimenetelmät paljastavat entistä tarkemmin mahdollisen rikin puutteen kasvissa. Englannissa kehitetyn malaattisulfaattitestin on todettu olevan perinteistä typpi/rikki - suhdetta tarkempi rikin puutteen paljastamisessa. Kemira GrowHow Oyj on tutkinut malaattisulfaattitestillä 2003 - 2004 satoja kasvustonäytteitä, joiden mukaan ohran rikkipitoisuudet ovat alle optimikasvun vaatiman tason joka kolmannessa tapauksessa. Noin $29 \%$ näytteistä oli kokeissa puutealueella. Nurmella rikkitilanne näyttää olevan parempi, vain muutama prosentti näytteistä oli puutealueella. Tämä ero kasvien välillä voi johtua esimerkiksi nurmen paremmin maan rikkivarat hyödyntävästä juuristosta tai nurmille useamman kerran kesässä annettavasta lannoituksesta, mikä estää ravinteen joutumista kasveille käyttökelvottomaan muotoon tai paikkaan. Ohrallakin puute näyttää harvoin olevan kovin paha, ennustetut satotappiot pysyvät yleensä 10 \% tasolla.

Edellä todetun perusteella rikin merkitys seurattavana kasviravinteena kasvanee lähivuosina. Koska rikki poikkeaa luonteeltaan normaalin viljavuusanalyysin muista ravinteista, nykyiseen viljavuusanalyysiin perustuva lannoitussuositus vaatii todennäköisesti hieman täydennystä. Kyseeseen voisi tulla esimerkiksi taselaskelma, joka arvioisi rikkilannoitustarvetta nykyisten suositusperusteiden lisäksi hyödyntämällä paikkatietoa säästä, rikkilaskeumasta ja maan vedenpidätysominaisuuksista. Pellolta huuhtoutumalla poistuvan rikin seuranta on erityisen tärkeää kasvukauden ulkopuolella, kun pellolla ei ole kasveja rikkiä ottamassa.

Asiasanat: rikki, rikkitase, peltoviljely 


\section{Johdanto}

Ravinnetutkimuksissa keskitytään usein typen ja fosforin vaikutuksiin satoon ja laatuun. Syynä tähän on todennäköisesti se, että näiden ravinteiden lisäannosten on todettu useimmiten vaikuttavan kasveihin ja ilman vuosittaista esimerkiksi lannoitteilla annettavaa ravinnetäydennystä satotasot lähtevät laskuun. Viime aikoina ravinteista vähemmälle huomiolle on jäänyt rikki. Rikki on määrällisesti fosforiin verrattava ravinne, jos asiaa tarkastellaan maksimikasvuun tarvittavina määrinä kasvissa. Osasyynä tämän päivän vähäiseen tutkimukseen ovat varmaankin 10 - 20 vuoden takaiset kokeet, joissa rikillä saatiin hyvin harvoin näkyviä vaikutuksia kasveihin. Siihen aikaan ilmasta tuli laskeuman mukana rikkiä maahan niin paljon, että se ja lannoitteissa annettu rikkimäärä riittivät pitämään maan rikkitason riittävänä kasveille. Toisaalta rikki on typen tavoin hankala ravinne perinteiselle maaperäanalyysille, koska sitä vapautuu maasta kasvien käyttöön pääasiassa mikrobitoiminnan seurauksena. Maanäytteen laboratorioanalyysissä esiin tuleva rikkipitoisuus muuttuu niin paljon näytteenoton ja analyysin välisenä aikana, että analyysituloksen hyöty ei yllä aivan samalle tasolle kuin esimerkiksi fosforilla tai kalilla.

\section{Muutokset kasveille käyttökelpoisen rikin määrässä viime vuosikymmeninä}

Viitteitä kasvien rikin puutteesta on alkanut ilmetä vasta aivan viime vuosina. Rikin puutteen yleistymistä on osattu odottaa muun muassa siksi, että aiemmin merkittävämpi rikkilähde eli rikkilaskeuma on pienentynyt oleellisesti vuoden 1980 noin $10 \mathrm{~kg} / \mathrm{ha}$ tasosta tämän päivän muutamaan kiloon hehtaarille (kuva 1).
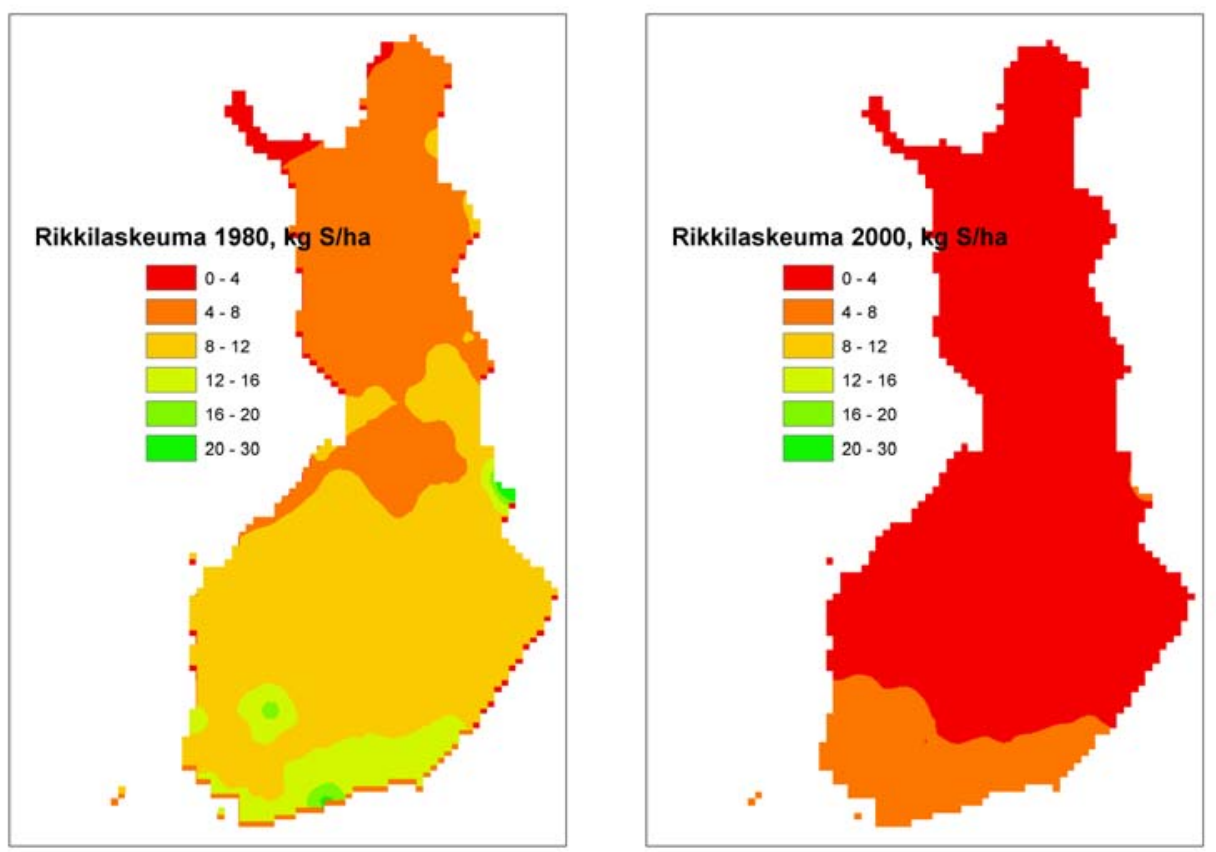

Kuva 1. Rikkilaskeuma (kg/ha) Suomessa vuosina 1980 ja 2000 (EMEP).

Pääosan pellon ulkopuolisesta rikkilisäyksestä muodostavat lannoitteet ja karjanlanta. Laskeuman pieneneminen on entisestään kasvattanut niiden merkitystä rikkilähteenä. Myös lannoitteiden mukana peltoon lisätyn rikin määrä on pienentynyt viimeisen 15 vuoden aikana, koska lannoitteiden käyttömäärät ovat laskeneet ja rikin keskipitoisuudet Suomessa käytetyissä lannoitteissa ovat pysyneet lähes samana. Kuvassa 2. on esitetty typpilannoituksen pieneneminen vuodesta 1990 lähtien (FINFOOD). 


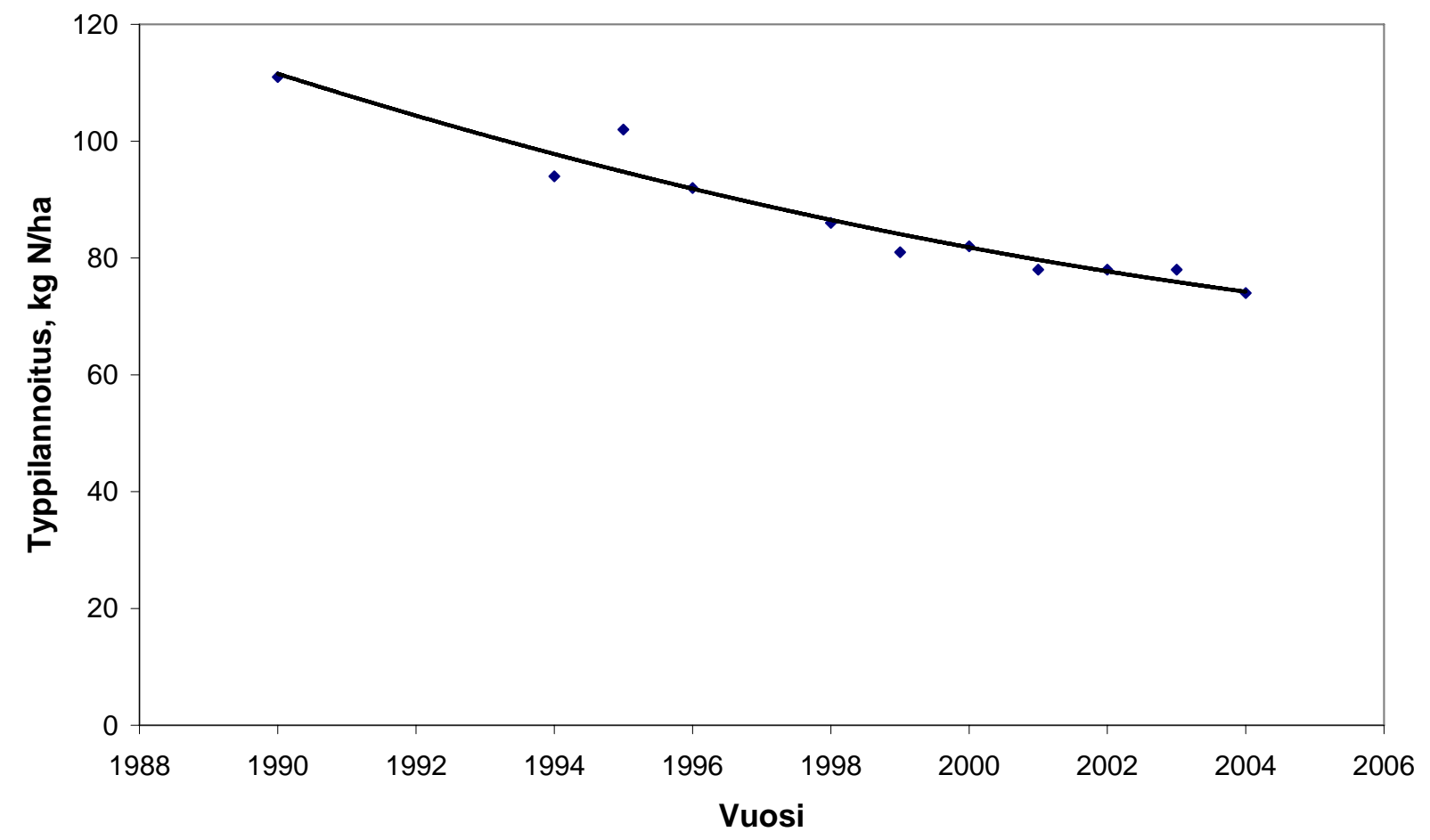

Kuva 1. Keskimääräinen typpilannoitus Suomessa vuosina 1990 - 2004 (mineraalilannoitteet).

Jos oletetaan keskimääräisen N/S suhteen olleen lannoitteissa vakio 10:1 tarkasteltavalla aikajaksolla, tänä päivänä peltoon lisätään noin 4 kg S /ha vähemmän kuin vuonna 1990. Lannoitteiden ja laskeuman mukana pelloille tuleva rikkimäärä on yhteensä suurin piirtein samansuuruinen kuin sadon mukana pellolta poistuva rikkimäärä. On myös otettava huomioon, että rikkilaskeuman käyttökelpoisuutta kasvinravinteena alentaa tosiseikka, että suuri osa laskeumasta tulee Suomessa maahan kasvukauden ulkopuolella. Suomen Ympäristökeskuksen julkaisemattoman aineiston mukaan 63 \% vuosittaisesta sulfaattilaskeumasta kertyi jakson toukokuu - elokuu ulkopuolella. Kun rikin huuhtouma Suomessa saattaa olla savimaillakin jopa $20 \mathrm{~kg} /$ ha vuosi, pelloilta poistuu rikkiä selvästi enemmän kuin mitä sinne lisätään (Jaakkola \& Turtola 1986). Vähemmän vettä pidättävissä maissa huuhtouma on todennäköisesti vielä suurempi. Oloissa, joissa maa ei jäädy talvella ollenkaan, rikin huuhtoumaksi on mitattu jopa 60 - 70 kg/ha (Mansfeld 1994, Preuschoff 1995).

\section{Rikkilannoituksen vaikutuksia viime vuosina tehdyissä kokeissa}

Laskennallisen puutetilariskin lisäksi modernit kehittyneet kasvianalyysimenetelmät paljastavat entistä tarkemmin mahdollisen rikin puutteen kasvissa. Malaattisulfaattitestin on todettu olevan perinteistä typpi/rikki - suhdetta tarkempi rikin puutteen paljastamisessa (Blake-Kalff ym. 2000). He esittivät, että malaattisulfaatti - arvon noustessa yli yhden satotappion riski nousee selvästi. Maa- ja elintarviketalouden tutkimuskeskuksessa järjestettiin kesällä 2005 astiakoe, jossa testattiin tätä kirjallisuudessa esitettyä kriittistä malaattisulfaatti - arvoa. Kokeen tulos oli hyvin samansuuntainen kuin Blake-Kalff et al. (2000) artikkelissaan esittivät (kuva 3). 


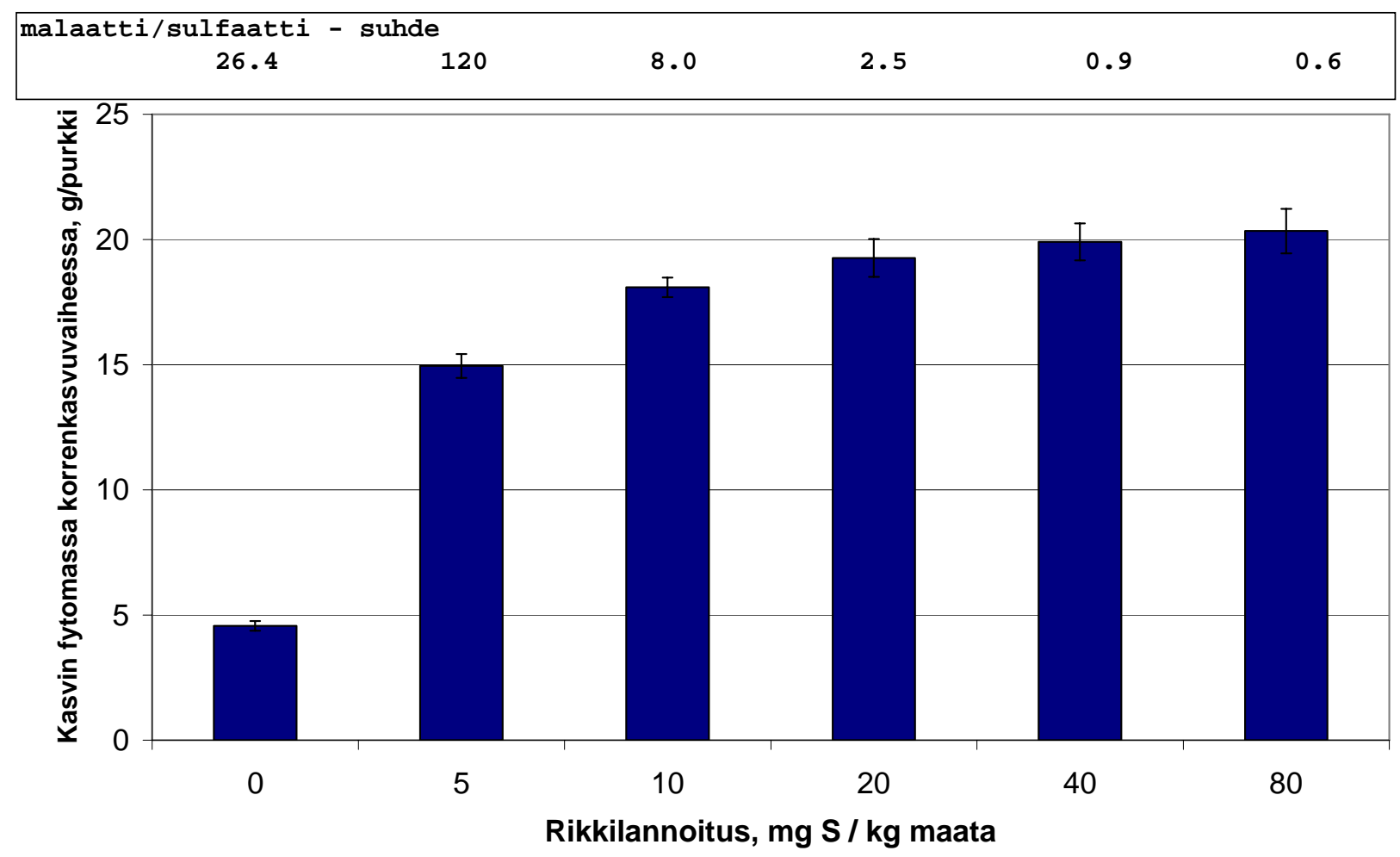

Kuva 3. Rikkilannoituksen vaikutus kevätvehnän fytomassaan ja malaatti-sulfaatti - arvoon korrenkasvuvaiheessa.

Kuvasta 3. näkyy, että malaatti-sulfaatti - suhde oli alle yksi koejäsenissä 40 ja 80 mg S/ kg maata, joissa rikkilannoitus ei näyttänyt enää nostavan fytomassaa eli rikki ei ollut rajoittava tekijä kasvulle toisin kuin alemmilla lannoitustasoilla. Sen sijaan kevätvehnän fytomassa alkoi pienentyä, kun lannoitusta pienennettiin alle $40 \mathrm{mg} \mathrm{S} / \mathrm{kg}$ maata. Samalla malaatti-sulfaatti - suhde alkoi kasvaa, mikä indikoi rikinpuutetta Blake-Kalff ym. (2000) mukaan.

Kemira GrowHow Oyj on tutkinut malaattisulfaattitestillä 2003 - 2004 satoja kasvustonäytteitä, joiden mukaan ohran rikkipitoisuudet ovat alle optimikasvun vaatiman tason joka kolmannessa tapauksessa. Noin 29 \% näytteistä oli kokeissa puutealueella. Nurmella rikkitilanne näyttää olevan parempi, vain muutama prosentti näytteistä oli puutealueella. Tämä ero kasvien välillä voi johtua esimerkiksi nurmen paremmin maan rikkivarat hyödyntävästä juuristosta tai nurmille useamman kerran kesässä annettavasta lannoituksesta, mikä estää ravinteen joutumista kasveille käyttökelvottomaan muotoon tai paikkaan. Ohralla malaattisulfaattitestin perusteella ennustetut satotappiot olivat yleensä $10 \%$ suuruusluokkaa.

Kasvukauden aikana kasvustosta tehtävillä mittauksilla voi siis ennakoida kehittymässä olevan sadon määrää ja laatua. Viljoilla mittaukset pyritään tekemään kehitysvaiheissa, jolloin lisälannoituksella tai kasvinsuojeluruiskutuksilla voidaan vielä näihin asioihin vaikuttaa. Viljoilla viimeinen tällainen kehitysvaihe on yleensä kukinta-aika. Ympäristötekijät vaikuttavat usein kuitenkin paljon sadon määrään ja laatuominaisuuksiin jyväntäytymisjakson aikana ja sadonkorjuuaikaan huomataan, että tehdyt ennusteet eivät pitäneetkään paikkaansa. Tämän vuoksi eri vuosina tai eri koepaikoilla järjestetyissä kokeissa satovasteet saattavat vaihdella huomattavastikin.

Kemira GrowHow Oyj:n koetilalla Vihdissä aloitettiin vuonna 2000 rikkilannoituskoesarja. Yksi koejäsen ei saa lannoiterikkiä ollenkaan, toisessa lannoitteen rikkipitoisuus on 3 \% ja kolmannessa 6 \%. Tässä kokeessa koeruudut on pidetty samassa paikassa vuodesta toiseen, koska on haluttu nähdä, missä vaiheessa rikinpuutos alkaa näkyä kasvustossa, jos rikkiä ei lisätä peltoon ollenkaan. Neljän ensimmäisen vuoden aikana koejäsenten satotasot olivat vaihtelevasti samalla tasolla, mutta kahtena viimeisenä vuotena 
rikkiä saaneet koejäsenet ovat tuottaneet rikitöntä korkeamman sadon (Kuva 4). Koesarjaa jatketaan, jotta nähdään, onko tämä satoero pysyvä.

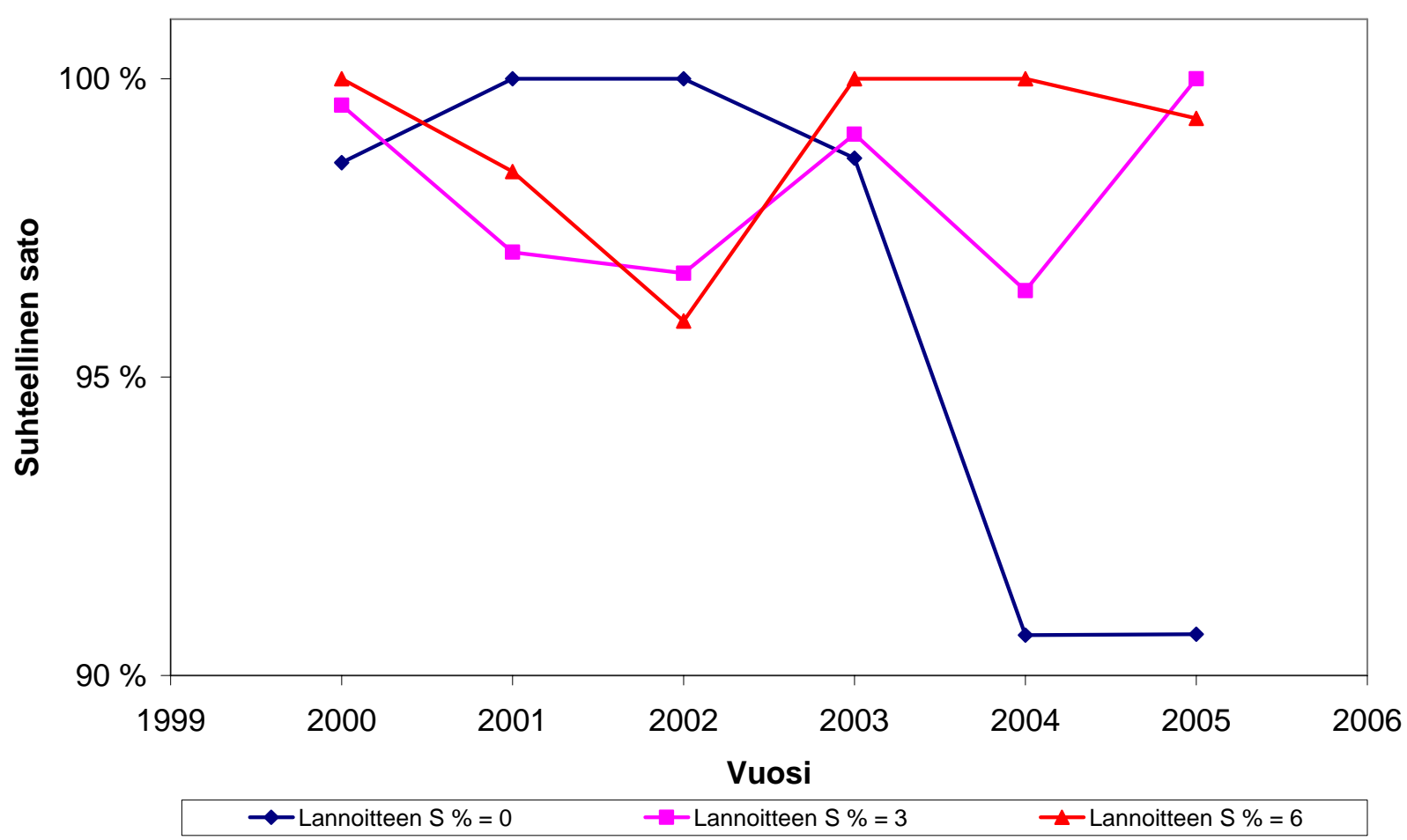

Kuva 4. Rikin lisäyksen vaikutus satoon Vihdissä vuosina 2000 - 2005. Kunakin vuonna verranteena (100 \%) on kokeen sen vuoden maksimisato.

\section{Tarvittavat toimenpiteet kasvien riittävän rikinsaannin turvaamiseksi}

Edellä todetun perusteella voi ennustaa, että rikin merkitys seurattavana kasviravinteena kasvaa lähivuosina. Koska rikki poikkeaa luonteeltaan normaalin viljavuusanalyysin muista ravinteista, nykyiseen viljavuusanalyysiin perustuva lannoitussuositus vaatii todennäköisesti hieman täydennystä, jotta kasvien rikin saannista saataisiin riittävän tarkka kuva. Rikkisuosituksen laskentaa voisi tukea esimerkiksi taselaskelmalla, joka arvioisi rikkilannoitustarvetta nykyisten suositusperusteiden lisäksi hyödyntämällä paikkatietoa säästä, rikkilaskeumasta ja maan vedenpidätysominaisuuksista. Pellolta huuhtoutumalla poistuvan rikin seuranta on erityisen tärkeää kasvukauden ulkopuolella, kun pellolla ei ole kasveja rikkiä ottamassa. Lisäksi kasvien rikkitilanne pitäisi ainakin riskialueilla ja - kasveilla selvittää kasvukauden aikana nykyaikaisilla menetelmillä, jotta mahdolliset puutokset pystyttäisiin korjaamaan ennen kuin satotappioita syntyy. Riskialueilla tarkoitetaan tässä alueita, joilla huuhtoumariski on joko maalajin ja/tai vallinneen sään takia suuri. Riskikasvit taas ovat kasveja, joilla rikintarve on muita suurempi eli lähinnä ristikukkaisia.

\section{Kirjallisuus}

Blake-Kalff, M.M.A, Hawkesford, M.J., Zhao, F.J. \& McGrath, S.P. 2000. Dianosing sulphur deficiency in field grown oilsee rape (Brassica napus L.) and wheat (Triticum aestivum L.). Plant and Soil 225, 95-107.

EMEP. EMEP Programme is Co-operative Programme for Monitoring and Evaluation of the Long-range Transmission of Air pollutants in Europe. www.emep.int.

FINFOOD. Tietovakka, Finfood - Suomen Ruokatieto ry, Vantaa.

Jaakkola, A. \& Turtola, E.1986. Viljelykasvin, lannoituksen ja sadetuksen vaikutus kaliumin, kalsiumin, magnesiumin, natriumin, sulfaattirikin sekä kloridin huuhtoutumiseen savimaasta. Maatalouden tutkimuskeskus, tiedote $17 / 86$. 
Mansfeld, T. 1994. Schwefeldynamik von Böden des Dithmarscher Speicherkoogs und der Bornhöveder Seenkette in Schleswig-Holstein. Dissertation, Christian Albrechts-Universität zu Kiel.

Preuschoff, M. 1995. Untersuchungen zur Schwefelversorgung von Weisskohl an zwei Lössstandorten. Dissertation, Univärsität Hannover, Verlag Ulrich E. Grauer, Stuttgart. 